\title{
Specific patterns of cognitive impairment in patients with idiopathic normal pressure hydrocephalus and Alzheimer's disease: a pilot study
}

\author{
J L Iddon, J D Pickard, J J L Cross, P D Griffiths, M Czosnyka, B J Sahakian
}

Department of

Psychiatry, MRC

Cambridge Centre for

Brain Repair,

University of

Cambridge, UK

$\mathrm{J}$ L Iddon

B J Sahakian

Department of

Neurosurgery

J D Pickard

M Czosnyka

Department of

Radiology

J D Pickard

J J L Cross

Section of Academic Radiology, University of Sheffield, UK

P D Griffiths

Correspondence to:

Dr JL Iddon, Department of

Academic Neurosurgery, Box

167 , University of

Cambridge, Addenbrooke's

Hospital, Hills Road,

Cambridge, CB2 5RG, UK

email jo.iddon@cenes.co.uk

Received 6 January 1999 and in revised form

6 July 1999

Accepted 15 July 1999

\begin{abstract}
Objectives-Eleven patients with idiopathic normal pressure hydrocephalus (NPH) were selected from an initial cohort of 43 patients. The patients with NPH fell into two distinctive subgroups: preshunt, group $1(n=5)$ scored less than 24 on the mini mental state examination (MMSE) and were classified as demented and group $2(n=6)$ scored 24 or above on the MMSE and were classified as nondemented.
\end{abstract}

Methods-All patients were neuropsychologically assessed on two occasions: preshunt and then again 6 months postshunt. Group 1 completed the mini mental state examination (MMSE) and the Kendrick object learning test (KOLT). In addition to the MMSE and KOLT, group 2 completed further tasks including verbal fluency and memory and attentional tasks from the CANTAB battery. Nine of the 11 patients also underwent postshunt MRI.

Results-Group 1, who, preshunt, performed in the dementing range on both the MMSE and KOLT, showed a significant postoperative recovery, with all patients now scoring within the normal nondemented range. Group 2, although showing no signs of dementia according to the MMSE and KOLT either preshunt or postshunt, did show a specific pattern of impairment on tests sensitive to frontostriatal dysfunction compared with healthy volunteers, and this pattern remained postoperatively. Importantly, this pattern is distinct from that exhibited by patients with mild Alzheimer's disease. Eight of the nine patterns of structural damage corresponded well to cognitive performance.

Conclusions-These findings are useful for three main reasons: (1) they detail the structural and functional profile of impairment seen in NPH, (2) they demonstrate the heterogeneity found in this population and show how severity of initial cognitive impairment can affect outcome postshunt, and (3) they may inform and provide a means of monitoring the cognitive outcome of new procedures in shunt surgery.

(F Neurol Neurosurg Psychiatry 1999;67:723-732)

Keywords: shunt; dementia; executive dysfunction
Normal pressure hydrocephalus (NPH) was first characterised in 1965 by Hakim and Adams $^{1}$ as ventricular dilation accompanied by a progressive triad of a gait disturbance, "dementia" and incontinence. It should be confirmed by the demonstration of a raised CSF outflow resistance. In terms of the physical symptoms, there is now a broad consensus in the literature ${ }^{23}$ that these can be successfully relieved by insertion of a CSF shunt in up to $65 \%-70 \%$ of patients with a known cause and $30 \%-50 \%$ of idiopathic cases. However, the precise nature of the mental changes and their response to shunt surgery is much less clearly defined.

The few studies of cognitive function in well characterised patients with NPH have generally reported significant improvements in general cognitive functioning after shunt surgery, particularly on memory tests..$^{4-7}$ Other studies have reported disproportionately poor performance on tests of executive functionthat is, tests that are sensitive to frontal lobe or frontostriatal dysfunction, preshunt and postshunt. $^{8-13}$

Historically acute hydrocephalus has been associated with reduced frontal cerebral blood flow, possibly as the result of stretching of the anterior cerebral arteries over the corpus callosum for which there is some angiographic and Doppler evidence. Ventricular enlargement may preferentially stretch the longest nerve fibres as they circumnavigate the ventricles, hence preferentially disturbing gait and bladder function. Projection of the cholinergic fibres from the nucleus basalis to the cortical neurons involved in memory might be stretched and could be involved in depressing $\mathrm{CBF}$ metabolism. However, evidence for a preferential reduction in frontal cerebral blood flow and oxidative/glucose metabolism in NPH is contradictory. It is difficult to compare series because of mixing of idiopathic with secondary cases and failure to base the diagnosis on robust techniques such as ICP monitoring and CSF outflow resistance measurements. Many of the tomographic techniques used are semiquantitative. In brief, five groups have reported no evidence of frontal hypoperfusion $^{14-18}$ whereas two groups described subcortical and inferior frontal/ temporal hypoperfusion. ${ }^{19} 20$ No consistent regional changes in cerebral oxygen or glucose consumption have been found by three separate groups using PET. $^{21-23}$ 
Magnetic resonance imaging techniques have been used to assess the effects of periventricular and deep white matter lesions on outcome after shunting. ${ }^{24}{ }^{25}$ Both studies concluded that, in general, the degree of improvement depends on the severity of damage to these different regions but that patients with severe white matter lesions may still benefit from shunting.

One of the problems with the characterisation of the dementia syndrome in NPH is that to a large extent it has perhaps been viewed as a single clinical entity. This is partly due to the fact that often basic measures such as the mini mental state examination (MMSE) are used as the only form of cognitive assessment. Although a useful initial examination for determining whether a patient falls into the dementing range, and the severity of dementia, it is the case that the MMSE is perhaps most useful for assessing whether the patient's general level of cognitive functioning is too low for other adult assessment techniques to be used. ${ }^{26}$ However, the MMSE is prone to ceiling effects and therefore is insensitive to assessment of specific facets of higher level cognition which tend to be early indicators of neurological change. It is often not possible to identify core deficits or to inform as to the dementia (frontostriatal or frontosubcortical, classic posterior cortical, etc). Therefore, more sensitive measures should be included. One example of neuropsychological tests designed for such use is the Cambridge neuropsychological test automated battery (CANTAB). This is a series of computerised tests completed by the patient via a touch screen. The tests are graded in difficulty to avoid floor and ceiling effects and have been shown to be highly sensitive to damage in different neural regions. ${ }^{27}$ CANTAB has been shown to be useful in the early detection of different forms of dementia. ${ }^{28-30}$ This is important as in most cases, once a patient has reached the stage at which they are clearly demented, so much permanent neural damage has already taken place that long term positive outcome may be rare. Therefore, if patients with NPH can be detected earlier and differentially diagnosed from other types of dementia, then long term prognosis is likely to be better. Clearly some of the previous studies already discussed in this paper have used more sensitive measures, including tests of executive function $^{8-13}$ and these may be useful if used in conjunction with imaging techniques. CANTAB also potentially provides a comparative benefit. If normal pressure hydrocephalus, or subgroups of it, have a specific profile of impairment, this may provide a useful basis for comparison with the classic posterior dementia, Alzheimer's disease, in addition to other forms of neurodegenerative disorders (such as Huntington's disease) or cortical damage (neurosurgical patients with frontal or temporal lobe lesions). In addition, the neural circuitry required for successful completion of some of the CANTAB tests is known from PET neuroimaging studies in normal volunteers. ${ }^{31}{ }^{32}$ It is still also the case that in most reported studies there is a great lack of clarity in the importance of early diagnosis and intervention and little mention of staging of dementia. It is likely to be the case that in many instances no formal neuropsychological assessment actually takes place at all.

Based on this previous neuropsychological evidence of apparently greater effect on tests of executive function, we selected tasks which were relatively sensitive or insensitive to frontal lobe function, to examine whether such tests were particularly susceptible to damage induced by NPH. We also included this combination of tests to inform us about the nature of the cognitive impairment in NPH by looking at patients who score out of the dementing range on the MMSE as well as comparing this group of patients with NPH with those for whom differential diagnosis presents a problem, patients with dementia of the Alzheimer type.

Our hypothesis was that early detection of $\mathrm{NPH}$ and differentiation from other types of dementia will facilitate early CSF drainage and hence improve prognosis. There may not be one single form of dementia syndrome in NPH but rather, there are varying degrees of cognitive change preshunt, according to the amount of permanent brain damage that has already taken place, compounded by comorbidity factors such as hypertensive cerebral small vessel disease. The success of the shunting procedure may well depend on the length of time before diagnosis has taken place. There were three main aims in the present study: (1) to quantify more specifically the nature of the cognitive impairment in NPH; (2) to determine the degree of improvement in patients with NPH to shunt surgery in relative regard to the degree of cognitive impairment preshunt; and (3) to assess performance on the tests compared with patients with mild dementia of the Alzheimer type (DAT) which presents as one major problem for the differential diagnosis with NPH.

\section{Patients and methods}

PATIENTS

Forty three patients were assessed, although only 11 were actually included in the study. Patients were excluded on the following basis: 10 did not undergo a shunt operation as after initial investigation (at which time they were also assessed by the neuropsychologist JLI) they were deemed not to have hydrocephalus. A further 17 were excluded due to concomitant factors including stroke $(n=3)$; partial sight $(n=2)$; nervous breakdown $(n=1)$; depression $(n=5)$; head injury $(n=1)$; brain haemorrhage $(n=1)$; subarachnoid haemorrhage $(n=1)$; and learning disability $(n=3)$. Four further patients were assessed preshunt but did not undergo a further postshunt assessment due to death $(n=2)$ or withdrawal from the study $(n=2)$. One patient had high pressure hydrocephalus and was excluded. All patients were referred by the same neurosurgeon for participation in the study (JDP) on the basis of a characteristic clinical picture of a typical gait disturbance, slowing of mentation, and/or short term memory disturbances (table 1). Imaging included CT in all patients (not reported) and 
Table 1 Individual subject details of normal pressure hydrocephalus patients from groups 1 and 2

\begin{tabular}{|c|c|c|c|c|c|c|c|c|c|c|c|}
\hline Case No & Age & Sex & $I Q$ & Aetiology & Gait disturb & Incontinence & $\begin{array}{l}\text { MMSE } \\
\text { Preshunt }\end{array}$ & $\begin{array}{l}\text { MMSE } \\
\text { Postshunt }\end{array}$ & ${ }^{R} O U T$ & $C V R F$ & $\begin{array}{l}\text { MRI white } \\
\text { matter score }\end{array}$ \\
\hline \multicolumn{12}{|c|}{ Group 1 (demented preshunt): } \\
\hline 1 & 69 & $\mathrm{M}$ & 109 & Idiopathic & Yes & Yes & 5 & 25 & - & None & - \\
\hline 2 & 62 & $\mathrm{~F}$ & 98 & Idiopathic & Yes & Yes & 5 & 27 & - & None & 24 \\
\hline 3 & 72 & $\mathrm{~F}$ & 102 & Idiopathic & Yes & Yes & 16 & 26 & 18 & None & - \\
\hline 4 & 73 & $\mathrm{~F}$ & enfl ${ }^{\star}$ & Idiopathic & Yes & No & 11 & 27 & - & None & 2 \\
\hline 5 & 75 & M & 108 & Idiopathic & Yes & Yes & 15 & 24 & 19 & None & 24 \\
\hline \multicolumn{12}{|c|}{ Group 2 (non-demented preshunt): } \\
\hline 6 & 74 & M & 121 & Idiopathic & Yes & No & 24 & 28 & - & None & 4 \\
\hline 7 & 65 & M & 107 & Idiopathic & Yes & No & 26 & 25 & 21 & Yes & 8 \\
\hline 8 & 72 & M & 115 & Idiopathic & Yes & Yes & 26 & 29 & 13 & Yes & 8 \\
\hline 9 & 56 & M & 94 & Idiopathic & Yes & No & 24 & 29 & - & None & 6 \\
\hline 10 & 75 & M & 108 & Idiopathic & Yes & No & 29 & 30 & 15 & None & 24 \\
\hline 11 & 73 & M & 101 & Idiopathic & Yes & No & 27 & 27 & - & yes & 0 \\
\hline
\end{tabular}

*enfl=English not first language; $\mathrm{MMSE}=$ mini mental state examination; $\mathrm{CVRF}=$ cardiovascular risk factors

MRI in nine patients. The diagnosis was confirmed in some patients by computerised CSF infusion studies - in the other patients the clinical presentation and scan were considered diagnostic without any evidence of deep white matter lesions. After ventriculoperitoneal shunting using either a Medos-Programmable or Delta level 1 valve, postoperative CT was performed to exclude any asymptomatic fluid collection of other complications. When patients did not improve, shunt function was checked by computerised CSF infusion studies and the shunt revised or a lower programmable setting used.

The eleven patients were divided into two groups: group $1 \quad(n=5)$ : demented idiopathic $\mathrm{NPH}$ assessed preshunt and postshunt; group $2(n=6)$ : non-demented idiopathic NPH assessed preshunt and postshunt; demented and non-demented were defined using the mini mental state examination ${ }^{33}$ with a score of 24 or above as non-demented and less than 24 as demented. Premorbid verbal IQ was measured using the national adult reading test (NART) ${ }^{34}$ and each patient was screened for depression using the Beck depression inventory ${ }^{35}$; see table 1 for a summary of the individual patient details and table 2 for group details.

\section{Patients with Alzheimer's disease}

For comparison purposes the mean performance of a group of patients with DAT was also included on the graphs on which the results of group 2 are shown. The details of this group can be seen in table 2 .

Healthy volunteers

To determine whether patients in group 2 were impaired on verbal fluency and the CANTAB tests preshunt, they were matched for age and premorbid verbal IQ (using the NART), to normal healthy volunteers. Each control was screened for neurological and psychiatric disorders and came from the Cambridge area. Table 2 outlines the mean subject characteristics for each of the groups included.

COGNITIVE ASSESSMENT PROCEDURE

The patients with NPH were assessed on two occasions. The first test session took place presurgery in Addenbrooke's Hospital, the second 6 months later in the patient's home. Patients in group 2 were able to complete all of the tasks outlined below; however, patients in group 1 were only able to complete some of the tasks due to the severity of their dementia, particularly at test session 1 . The initial psychometric assessment comprised traditional neuropsychological measures (as outlined below). A subset of contemporary tasks were then administered from CANTAB. These tasks are administered via a touch sensitive portable computer. The experimenter controlled the computer and gave verbal instructions to the subject for each task. The subject was comfortably positioned about $0.5 \mathrm{~m}$ in front of the touch screen and the procedure was explained-that is, that they would have to respond to stimuli on the screen by touching them. To introduce the subjects to the apparatus, they were initially given a motor screening task in which they were asked to respond to a series of 10 flashing crosses presented at different locations on the screen one by one, by placing the index finger of their writing hand on the centre of each cross. As well as relaxing the subject, this also screens for movement and visual problems and ensures that the subject can understand instructions. When the subject had understood this and was confident in interacting with the computer, the other CANTAB tests (outlined below) were given. Most of these tests have been standardised on an adult elderly population ${ }^{36}$ and have been shown to be resilient to the effects of practice in several studies. ${ }^{37}$ Parallel forms were administered at

Table 2 Mean subject characteristics of NPH groups 1 and 2, matched controls for group 2, and a comparison group of Mild DAT patients taken from Sahakian et al ${ }^{44}$

\begin{tabular}{lllll}
\hline Group & $n$ & Mean age & $\begin{array}{l}\text { Mean verbal IQ (national adult } \\
\text { reading test) }\end{array}$ & Mean MMSE preshunt \\
\hline 1 & 5 & $70.2(5.07 ; 62-75)$ & $104.25(5.2 ; 98-109)$ & $10.4(5.3 ; 5-16)$ \\
2 & 6 & $69.2(7.4 ; 56-75)$ & $107.7(9.6 ; 94-121)$ & $26.0(1.9 ; 24-29)$ \\
Controls group 2 & 6 & $68.5(8.5,56-77)$ & $110.2(8.3 ; 98-122)$ & - \\
$\begin{array}{l}\text { Mild DAT } \\
\left.\text { (from Sahakian } e a^{44}\right)\end{array}$ & 12 & $69.7(\mathrm{SEM}=1.8)$ & $118.0(\mathrm{SEM}=2.0)$ & $22.8(\mathrm{SEM}=1.3)$ \\
\hline
\end{tabular}

For groups 1 and 2 and controls the SD and range of figures are in parentheses. 
retest and these have been shown to be equivalent. ${ }^{39}$ All patients gave informed consent and the study was approved by the local ethics committee as well as being seen as part of audit. The procedure was explained and their informed verbal consent obtained. The patients were free to withdraw from testing at any time without explanation.

\section{ASSESSMENT SCALES}

Mini mental state examination ${ }^{33}$

This is a gross 30 item screening instrument, useful for the detection of dementia and for scoring severity of dementia. It includes assessments of personal orientation, immediate and delayed memory recall, attention and calculation, language, reading writing, and copying skills. Dementing range $0-23$, non-dementing range 24-30.

\section{Kendrick object learning test ${ }^{40}$}

This is a task designed to assess dementia status and memory performance. Four cards with $10,15,20$, and 25 pictures are shown individually for $30,45,60$, and 75 seconds. When each card is taken away the subjects are asked to name as many pictures on the card as they can remember. Dementing range $=0-22$, nondementing range $=23$ and above.

Beck depression inventory ${ }^{35}$

This consists of a 21 multiple choice depression screening questionnaire assessing somatic and psychological states.

Verbal fluency ${ }^{41}$

This task is administered in two parts. First subjects are required to generate as many words as possible beginning with three letters $(\mathrm{F}, \mathrm{A}$, and $\mathrm{S}$ ) giving a 1 minute time limit for each letter. The rule is that no names of people or places should be mentioned. This part of the task has been shown to be impaired in patients with frontal lobe damage. The second part of the task (category) requires the naming of as many animals as can be thought of beginning with any letter in 1.5 minutes. This part is relatively insensitive to frontal lobe damage but is impaired in patients with temporal lobe damage or Alzheimer's disease. All words are recorded on a test sheet divided into 10 second boxes for each different category. Two main scores were obtained for the purposes of this paper: (1) total number of different words produced for the letter category and (2) total number of animals named. Scores were compared with the Benton and Hamsher norms ${ }^{26}$ as well as to age and IQ matched controls.

\section{Computerised tests from the Cambridge neuropsychological test automated battery (CANTAB)}

Pattern recognition - This is a test of visual recognition memory, sensitive to temporal lobe damage and amygdalohippocampal excision $\mathrm{s}^{42}$ and patients with mild Alzheimer's disease. ${ }^{30} 44$

Twelve patterns are presented onto the centre of the screen in a box one after the other. The subject is instructed to watch the patterns carefully and to try to remember them. All twelve patterns then reappear individually and in reverse order but this time are paired with a novel pattern. The subject has to touch the pattern that has appeared before. This procedure is then repeated for a second set of 12 patterns. Maximum score $=24$, over two blocks.

Spatial recognition-This is a test of spatial recognition memory, sensitive to mild $\mathrm{DAT}^{44}$ and frontal lobe damage but is relatively insensitive to temporal lobe damage. ${ }^{31424345}$

Five empty white boxes are presented one by one onto the screen in different spatial locations. Subjects are instructed to remember the position that each box has appeared on the screen. The boxes then reappear individually in reverse order, paired with another box that appears in a novel location. The subject is asked to touch the box that has appeared in the same location as before. There are four sets in total; maximum score $=20$, over four sets.

Spatial span-This is a computerised version of the Corsi block tapping test ${ }^{46}$ designed to assess short term memory capacity for spatial information. It has been shown to be relatively insensitive to frontal lobe damage. ${ }^{42}$

A screen full of squares appears and initially two of these change colour in turn. The subject is required to remember the order in which the boxes change colour, wait for a tone to sound, and then repeat the sequence immediately. If the sequence is repeated correctly a new trial begins, this time with three boxes to remember. This process continues up until a maximum of nine boxes if the subject continues to copy the sequences correctly. If the sequence is not repeated correctly, the same level of boxes that has already been reached will be repeated in the next set, but will be presented in a different order each time. If the new level is not repeated correctly after three trials, the computer will automatically terminate the task. If it is the computer proceeds to the next level. The final score obtained is the last (highest) level passed.

ID/ED attentional set shifting paradigm-This is a task designed to assess cognitive flexibility, requiring the formation and shifting of attentional set. It is sensitive to frontal lobe damage and different forms of frontostriatal dysfunction, ${ }^{47}$ but relatively unimpaired in mild DAT. ${ }^{44}$

This complex task requires the subject to learn in succession a set of discrimination tasks in which one of two stimuli is correct and the other is not, on the basis of feedback provided by the computer after each choice. The main aim is to compare the capacity to make attentional shifts to exemplars within the same stimulus dimension currently attended (intradimensional shift) with shifts to the currently non-attended dimension (extradimensional shift). The test has some similarities to the Wisconsin card sorting test (WCST), but with a tighter control over the experimental contingencies which enables the parcellation of the various components of the WCST in the context of learning theory. For a full description of this test refer to Downes et al. ${ }^{47}$ The number of errors made cumulatively throughout the task and the stage at which the subject failed were used as the measurements for this 

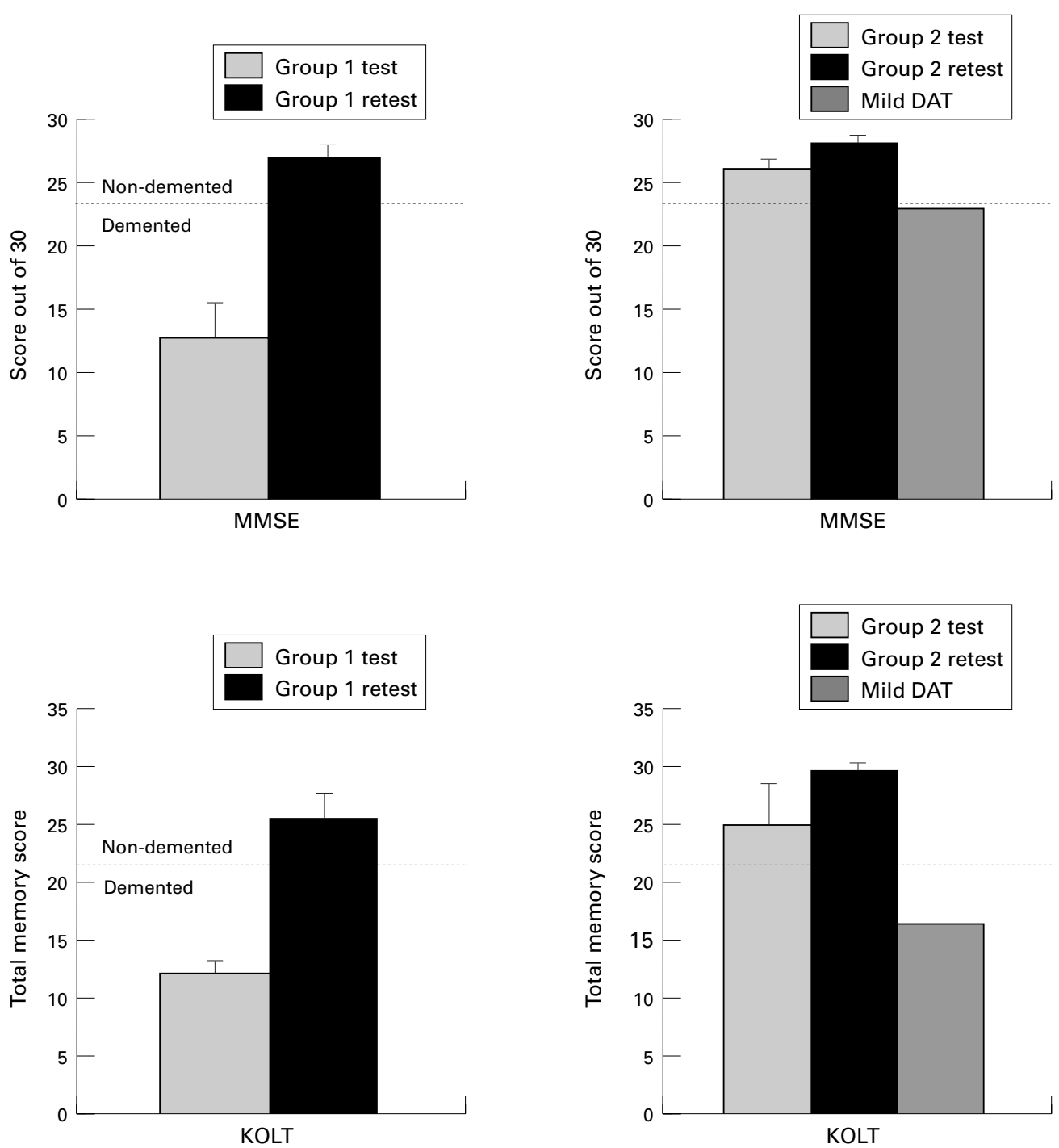

Figure 1 Performance of NPH groups 1 and 2 on the mini mental state examination and Kendrick object learning test before and 6 months after the shunt.

study. Failure at any stage automatically incurred 25 errors for each further stage.

Magnetic resonance imaging protocol

Patients were examined using either a GE Signa $0.5 \mathrm{~T}$ or $1.5 \mathrm{~T}$ MRI installation (General Electric, Milwaukee, USA). Axial and coronal proton density and T2 weighted images were obtained. The images were interpreted by two radiologists (JJC and PDG) who were blinded to the cognitive test results.

The white matter of each cerebral hemisphere was divided arbitrarily into four regions of interest. At the level of the lateral ventricles, the white matter was divided into anterior, middle, and posterior regions. The white matter superior to the lateral ventricles was considered as a separate region.

White matter signal abnormalities were scored according to the semiquantitative scale originally described by Fazekas ${ }^{49}$ Normal white matter was scored as 0 , lesions less than $5 \mathrm{~mm}$ in diameter were scored as 1 , lesions between 5 and $10 \mathrm{~mm}$ in diameter were scored as 2 , and confluent areas of signal change were scored as 3. Scores were allocated for the four regions of interest in both cerebral hemispheres. The maximum score for each patient was therefore 24.

\section{DATA ANALYSIS}

Most of the experimental data were analysed using the statistical package STATVIEW. Two tailed Student's paired $t$ tests were applied to test significance of differences between means comparing results within subjects for presurgery and postsurgery assessments. Comparisons were also made on the CANTAB tests between group 2 (session 1- preshunt) and control scores using unpaired $t$ tests.

\section{Results}

GROUP 1 (DEMENTED PRESHUNT)

On the MMSE dementia scale all patients scored within the moderate-severe dementing range preshunt (10.4 (SD 5.3)) but all scored within the normal range postshunt (25.8 (SD 1.3), fig $1 \mathrm{~A}$ ) an improvement of $51 \%$ which was highly significant ( $t \quad(4)=5.9$, $\mathrm{p}<0.01)$. Four of the five patients were also able to complete the KOLT (fig $1 \mathrm{~B}$ ) at both test sessions. At session 1 all scores fell within the 
Table 3 Mean pattern and spatial recognition, spatial span and ID/ED total error scores for the NPH group 2 patients, matched controls, and comparison data from mild DAT patients taken from Sahakian et $a l^{44}$ and Sahgal et al ${ }^{51}$

\begin{tabular}{|c|c|c|c|c|}
\hline Test & Group 2 test & Retest & Controls & $D A T$ \\
\hline Pattern recognition & $19.3(2.3)$ & $19.8(2.0)$ & $19.1(1.2)$ & Impaired (Sahakian et $a l^{44}$ ) \\
\hline Spatial recognition & $13.5(1.0)$ & $14.1(2.1)$ & $15.9(1.3)$ & Impaired (Sahakian et $a l^{44}$ ) \\
\hline Spatial span & $4.0(0.9)$ & $4.8(0.7)$ & $5.0(0.63)$ & $3.83\left(\right.$ Sahakian $\left.^{44}\right)$ \\
\hline IDED total errors & $47.17(16.2)$ & $62.3(18.4)$ & $27.5(15.5)$ & $\begin{array}{l}\text { Unimpaired (Sahgal et al }{ }^{51} \text { ) } \\
\text { (No mean scores reported) }\end{array}$ \\
\hline
\end{tabular}

The values in parentheses are SD.

dementing range $(<22)$ scoring 12.6 (SEM 1.1 ), at retest all of these scores were in the non-dementing range $(>22)$ with an average score of 26.4 (SEM 2.3). This improvement was again highly significant $(t \quad(3)=5.66$ $\mathrm{p}<0.01)$. The remaining patient was able to complete the KOLT, scoring within the nondementing stage at session $2($ score $=26)$. Some of the patients in this group were able to attempt one or two other tests from the battery either preshunt or postshunt. However, all individual performances were severely impaired - that is, at or below chance level.

GROUP 2 (NON-DEMENTED PRESHUNT) Preoperative compared with postoperative psychometric assessments

Figure $1 \mathrm{C}$ shows that the patients did not perform in the dementing range on the MMSE dementia scale either preoperatively (26.0 (SD 1.9)) or postoperatively (28.0 (SD 1.8)). These scores were not significantly different $(t$ $(5)=2.07, p=0.09)$. At test session 1 there was an average KOLT raw score of 24.8 (SD 9.4), and at test session 2 of 29.7 (SD 9.1, fig 1 D). These scores were not significantly different $(t$ $(5)=0.94 \mathrm{p}=0.39)$. According to the Benton and Hamsher norms for the verbal fluency task, ${ }^{26} 80 \%$ of the patients were impaired on the FAS letter part of the task preoperatively and $70 \%$ postoperatively. There was no significant change across test sessions ( $t(5)=0.95$, $\mathrm{p}=0.39$ ). On the category (animal) section of the task $50 \%$ were impaired preoperatively and $40 \%$ were impaired postoperatively; again there was no significant change across test sessions $(\mathrm{t}(5)=1.62, \mathrm{p}=0.18)$. Scores on the verbal fluency task were also compared with matched controls: patients from group 2 produced significantly fewer words beginning with FAS ( $\mathrm{t}(10)=3.8, \mathrm{p}<0.01$ ) (mean group $2=25.2$ (SD 8.2); controls 38.6, (SD 2.9)), but were not impaired at semantic fluency (naming animals) (t $(10)=0.00, \mathrm{p}=1.0)$ (mean group $2=20.0$ (SD 6.6); controls 20.0 (SD 1.4)).

Preoperative compared with postoperative CANTAB assessments

This showed no significant shunt improvement on the pattern $(t(5)=0.69, \mathrm{p}=0.5)$ or spatial $(t$ $(5)=0.58, \mathrm{p}=0.59)$ recognition tasks (table 3 ). There was also no difference on the ID/ED attentional task total adjusted errors ( $t$ $(5)=0.86$, p $=0.43$, fig 2$)$. On the ID/ED attentional task $83 \%(5 / 6)$ of the patients failed at the ED shift preoperatively, and $67 \%$ (4/6) also failed at the ED shift stage postoperatively with one person failing at the earlier ID shift stage; see table 3 for summary of mean scores at test

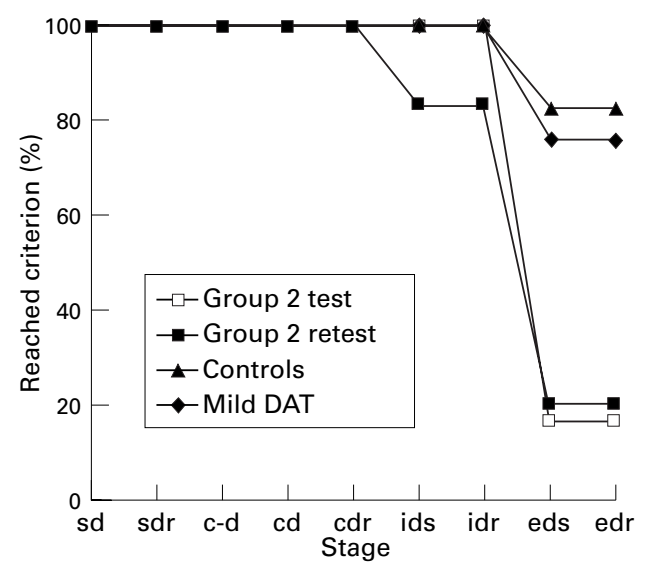

Figure 2 Performance of NPH group 2, matched controls and patients with mild dementia of the Alzheimer type (taken from Sahakian et al ${ }^{44}$ on the computerised IDED attentional set shifting task.

and retest. There was a significant difference on spatial span $(t(5)=2.7, \mathrm{p}<0.05)$ with a slight improvement at stage 2 (mean span at test $=4.0$ (SD 0.9); retest $=4.8$ (SD 0.7)). Thus the impairment on tests sensitive to frontal dysfunction remained postshunt.

Group 2 compared with controls on CANTAB preoperatively

This showed that patients were unimpaired on pattern recognition $(t(10)=0.16, \mathrm{p}=0.86)$, and spatial $\operatorname{span}(t(10)=2.13, \mathrm{p}=0.056$, table 3$)$. However, they were impaired on the spatial recognition task $(t(10)=2.73, \mathrm{p}<0.05)$ and on the ID/ED attentional set shifting task total errors score $(t(10)=2.25, \mathrm{p}<0.05$, table 3$)$. Figure 2 shows the cumulative proportion of patients succeeding at each stage of the task. $83 \%(5 / 6)$ of group 2, compared with $16.7 \%$ (1/6) of control patients successfully passed the test at the extra dimensional shift phase. Patients in this group were impaired on tests previously shown to be sensitive to frontal dysfunction, but sensitive to damage in more posterior cortical regions (pattern recognition).

It was shown by Sahakian et $a l^{30}{ }^{44}$ that compared with matched control subjects, patients with dementia of the Alzheimer type were significantly impaired in their performance on the pattern recognition and spatial recognition tasks, but not on the ID/ED attentional set shifting task (fig 2).

\section{RESULTS OF MRI}

Extent of white matter abnormalities

The white matter scores for individual patients are summarised in table 1 . Of three patients in group 1 who underwent MRI, two had widespread white matter disease (scores $=24$, 24) and one had few white matter lesions $($ score $=2)$.

Of six patients imaged from group 2 , five had few white matter lesions (scores $=0,4,6,8,8$ ) and one had widespread white matter disease (score $=24)$.

Distribution of white matter abnormalities There was no difference in the anatomical distribution of white matter lesions between the two groups. In particular there was no excess of 


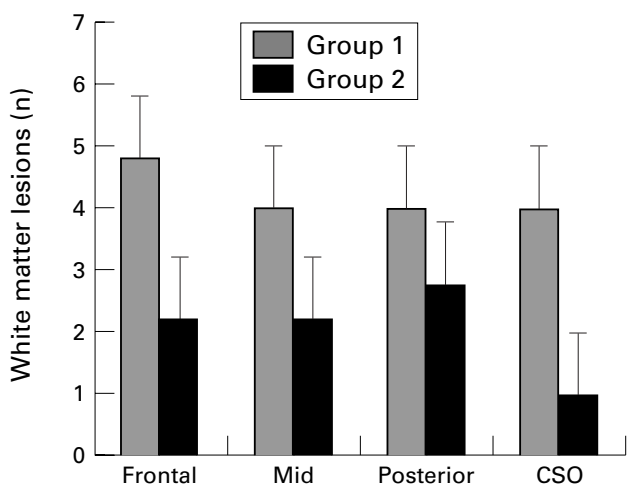

Figure 3 Distribution of white matter lesions for groups 1 and 2 .

white matter signal abnormalities in the anterior region of interest in patients in group 2 (fig 3).

\section{Discussion}

Distinctive and specific patterns of cognitive change were associated with the two groups of patients, according to disease severity. Group 1 initially presented with moderate to severe dementia preshunt but showed an impressive reversal of dementia postshunt. This was in keeping with comments by the patients and their relatives (although this was not formally assessed) about the large improvements in activities of daily living - for example, washing, dressing, and cooking. However, all but one of the patients remained severely impaired on all other cognitive tasks administered. Patients in preshunt group 2 were not demented but exhibited impairment on tests of executive function, while remaining unimpaired on tests relatively insensitive to frontal lobe damage. Postshunt, group 2 improved significantly on the dementia rating scales (within the nondementing range) possibly reflecting either some mild degree of general improvement or alternatively familiarity with the test, but exhibited the same degree and pattern of impairment on tests of frontal lobe function, the hypothesis being that the frontal executive impairment is not reversible. It also cannot be discounted that the few patients in group 2 may account for the failure towards improvements on some of the tests to reach significance. These results are relevant to other test hypotheses concerning the heterogeneity of cognitive deficits in NPH and the efficacy of the shunt procedure.

Patterns of structural change on the MRI corresponded well with the patterns of functional change in seven out of the nine patients who underwent the procedure. Of the two exceptions, case 4 had little white matter damage and improved the most of group 1, managing to complete some of the more difficult tasks, although remaining significantly impaired. By contrast case 10 showed extensive white matter changes and yet was not demented preshunt and performed well on the cognitive tests, showing only impairment on the tests sensitive to frontal executive dysfunction. Despite these two exceptions, the use of MRI (to assess structural change) and the neu- ropsychology (to assess functional change) were a useful combination to obtain a broader picture of these patients.

The improvement on dementia rating scales (by $51 \%$ ) in group 1 is much greater than that previously reported by Stambrook et al using the MMSE in which patients only improved by $15 \%$ from an average of 15 to 20 . This may reflect a difference in the types of patient selection criteria as well as the cause of the hydrocephalus. For example, in the present study computerised ICP monitoring and CSF outflow resistance measurements were used in conjunction with clinical presentation and scan and all of the cases were idiopathic. The selection criteria used by Stambrook et al was based on clinical and CT data and although some of the cases of hydrocephalus were idiopathic, some were not, with the hydrocephalus being attributable to other factors including subarachnoid haemorrhage, craniocerebral trauma, and craniotomy. Such differences do emphasise the complex nature of assessing these patients and highlights how important it is to be clear when describing selection and inclusion criteria in subgroups of patients. The fact that patients in group 1 were impaired on other tests of cognitive function may indicate a high level of permanent neural damage that has occurred. This would be in keeping with the studies ${ }^{24}{ }^{25}$ which found that the degree of postshunt improvement was dependent on the severity of the damage preshunt. It should also be noted that these were a continuous series of patients, thus differences in levels of improvement were not due to selection bias as all of the patients seen in group 1 were subsequently followed up for retest.

The pattern of spared and impaired function seen in the non-demented patients of group 2 is of particular significance given the important dissociations that have been found on the various computerised tasks. Owen $e t a l^{43}$ showed that there was no impairment on the pattern recognition task when completed by patients with frontal lobe damage. By contrast, this task was sensitive to temporal lobe lesions ${ }^{43}$ and has also been found to be impaired in even mild DAT. ${ }^{30}$ Patients with frontal lobe excisions are impaired on the spatial recognition task but performance remains relatively preserved on the spatial span task. ${ }^{42}{ }^{43}$ Deficits on similar spatial span task have been associated with damage to right posterior lesions, as well as parietal cortex, and spatial span has been shown to be impaired in patients with mild and moderate DAT. ${ }^{50-52}$ The patients with NPH failed at the ED shift stage of the ID/ED attentional task, similar to patients with frontal lobe excision and patients with frontosubcortical dementias such as Parkinson's disease, ${ }^{4547485}$ and Huntington's disease $^{54}$ which may possibly reflect a deficit in cognitive flexibility due to perseveration. ${ }^{36}$ This again is by contrast with many patients with mild DAT who were unimpaired compared with controls on this task. ${ }^{44}$ However, it is acknowledged that although such dissociations are informative, it is often difficult in research on dementia of various kinds to discriminate true differences in patterns of performance, from effects of differing severities or stages of dementia. 
These results in the non-demented patients with NPH suggest a specific pattern of impairment of critical executive functions, which cannot be relieved by shunt, compared with unimpaired performance on tasks with a smaller executive component. These findings are important because such functions are essential for effective performance in a complex world and have implications for real life functions such as decision making and social cognition..$^{55}$ Many investigators now agree that the prefrontal cortex is essential for tasks requiring reasoning, anticipation, goal establishment, strategy formation, shifting mental set, and error monitoring. ${ }^{567}$ These terms are often subsumed under the heading executive function. Mega and Cummings ${ }^{58}$ have also studied neuropsychiatric disorders associated with frontal dysfunction which as well as including impaired executive function can also result in disinhibition, apathy, mania, and lability, similar to that often seen in patients with NPH.

The results are also in keeping with those of other neuropsychological studies which have reported frontal lobe involvement in NPH. Caltagirone et $a l^{\beta}$ administered a mental deterioration battery to patients preshunt and postshunt and found that they were impaired on tests purported to assess frontal lobe involvement. Gustafson and Hagberg ${ }^{9}$ reported a similar finding both in terms of cognitive and emotional disturbances. Gustafson and Hagberg, ${ }^{9}$ Thomsen et al, ${ }^{11}$ Cummings et al, ${ }^{12}$ and Whitehouse ${ }^{59}$ all suggested that the mental deficit is of the "subcortical" type, resembling that seen in frontal disorders. Some but not all neuroimaging studies support the finding of a specific frontal involvement in the changes found (see Introduction).

Theoretically, there are several explanations for the dysfunction of the frontal lobe and its associated circuitry in the NPH syndrome. Firstly, if reduced regional cerebral blood flow $(\mathrm{rCBF})$ was a consistent finding, which it is not, a vascular mechanism might underlie both clinical features and $\mathrm{rCBF}$ reduction. The unified concept was that the ventricular enlargement caused stretching of the anterior cerebral artery and its branches over the corpus callosum. Secondly, the pattern of cognitive impairment seen in these patients with NPH is suggestive of impairment in functioning of frontosubcortical mechanisms. ${ }^{60}$ The findings of Waldemar et $a l^{19}$ and also Graff-Radford et $a l^{14}$ give support to this hypothesis as they reported subcortical blood flow abnormalities. Given that the cognitive changes are apparent before shunt, but remain afterwards even when the pressure has been relieved, this suggests irreversible damage to such circuits. In terms of the progression of the disorder, the early stages of NPH would result in this specific frontal pattern of mental impairment, but if the pressure is not relieved quickly by a shunt, the functional deficits would then broaden to include a more severe and global pattern of both cortical grey and subcortical white matter change, so causing a severe and permanent change in all aspects of mental functioning ${ }^{12}$ - for example, as seen in group 1. One confirmatory point relates to incontinence. It is only as patients become more severely ill that they experience this symptom (table 1).

The finding that in the early stages of $\mathrm{NPH}$ the pattern of cognitive impairment is predominantly frontosubcortical, only later becoming more global, contrasts markedly with the pattern in patients with Alzheimer's disease. ${ }^{44}{ }^{61}$ In this study the results of the patients with mild DAT have been added to the graphs as a comparison of patterns of performance. The patients with DAT were matched for age although they had a higher mean verbal IQ than the NPH patients but performed more poorly on the MMSE and KOLT. The two patient groups showed distinctly different patterns of performance with the NPH patients showing impaired performance on spatial recognition, as well as on the IDED attentional set shifting task, while remaining unimpaired on pattern recognition and spatial span. By contrast, the patients with mild DAT were impaired on the pattern and spatial recognition tasks and spatial $\operatorname{span}^{51}{ }^{52}$ but were unimpaired on the IDED task. ${ }^{44}$ It is, however, acknowledged that conclusions about patterns of performance based on small samples such as these must be tentative. Golomb et $a l^{62}$ found that hippocampal size strongly correlates with severity of dementia as determined by the MMSE score, showing that there is a smaller degree of atrophy of the hippocampal formation in many patients with NPH compared with controls and patients with DAT. This is also in keeping with the finding that there is no hippocampal atrophy in classic cases of NPH. ${ }^{3}$

$\mathrm{NPH}$ and DAT are often confused because of their initial presentation with similar patterns of cortical ventricular change and complaints of deteriorating memory. NPH is treatable and trials of novel drug treatments for DAT require accurate diagnosis. A greater understanding of the neuropsychology of NPH might also aid in the fine tuning of shunts and the development of novel techniques, as cognitive decline can often be detected before physical changes become apparent.

In summary, the results of this study show that there are two distinctive patterns of cognitive change in patients with NPH. Shunting may reverse dementia in patients who are demented according to gross measures (MMSE, KOLT) preshunt, but despite this improvement, significant cognitive impairment remains. In non-demented patients a specific pattern of executive impairment is found preshunt. This is not reversed as a result of shunting and does not change or recover over time. This pattern is distinct from that observed in patients with mild Alzheimer's disease.

We are grateful to Professor TW Robbins for his helpful comments on the manuscript. We also thank Christine McGowan, Colette O'Kane, and Jo Copeman for their help in contacting patients and organising appointments. This research was supported by a Major Award from the Wellcome Trust to Professors TW Robbins and BJ Everitt and Drs BJ Sahakian and AC Roberts. Dr JL Iddon was supported by the Wellcome Trust at the time of this research. Professor JD Pickard is supported by the Medical Research Council. 
1 Hakim S, Adams RD. The special clinical problem of symptomatic hydrocephalus with normal cerebrospinal fluid pressure. Observations on cerebrospinal fluid hydrodynamics. F Neurol Sci 1965;2:307-77.

2 Pickard JD. Normal pressure hydrocephalus. In: Swash M, Oxbury J, eds. Clinical neurology. Edinburgh: Churchill Livingstone, 1991;1:151-64.

3 Vanneste JAL. Three decades of NPH: are we wiser now? $\mathcal{F}$ Neurol Neurosurg Psychiatry 1994;57:1021-5

4 Malm J, Kristensen B, Karlsson T, et al. A predictive value of cerebrospinal fluid dynamic tests in patients with the idiopathic adult hydrocephalus syndrome. Arch Neurol 1995; 52:783-9.

5 Chen IH, Huang CI, Liu HC, et al. Effectiveness of shunting in patients with normal pressure hydrocephalus predicted by temporary, controlled resistance continuous predicted by temporary, controlled resistance continuous try 1994;57:1430-2.

6 Raftopoulos C, Deleval J, Chaskis C, et al. Cognitive recovery in idiopathic normal pressure hydrocephalus: ery in idiopathic normal pressure hydrocephal
prospective study. Neurosurgery 1994;35:397-405.

prospective study. Neurosurgery 1994;35:397-405.
7 Stambrook M, Cardosa ER, Hawryluk GA, et al. Neuropsychological changes following the neurosurgical treatment of normal pressure hydrocephalus. Arch Clin Neuropsychology 1988;3:323-30.

8 Caltagirone C, Gainotti G, Masullo C, et al. Neurophysiological study of normal pressure hydrocephalus. Acta Psychiatr Scand 1982;65:93-100.

9 Gustafson L, Hagberg B. Recovery of hydrocephalic dementia after shunt operation. F Neurol Neurosug Psychiatry $1978 ; 41: 940-7$

10 Berglund M, Gustafson L, Hagberg B. Amnesticconfabulatory syndrome in hydrocephalic dementia and korsakoff's psychosis in alcoholism. Acta Psychiatr Scand 1979;60:323-33.

11 Thomsen AM, Borgeson SE, Bruhn P, et al. Prognosis of dementia in normal pressure hydrocephalus after a shunt dementia in normal pressure hydrocepha

12 Cummings JL, ed. Subcortical dementia. Oxford: Oxford University Press, 1990:1.

13 Torkelson RD, Leibrock LG, Gustavson JL, et al. Neurological and neuropsychological effects of cerebrospinal fluid shunting in children with assumed arrested (normal pressure) hydrocephalus. I Neurol Neurosurg Psychiatry 1986;48:799-806.

14 Graff-Radford NR, Rezai K, Godersky JC, et al. Regional cerebral blood flow in normal pressure hydrocephalus. $\mathcal{F}$ Neurol Neurosurg Psychiatry 1987;50:1589-96.

15 Vorstrup S, Christensen J, Gjerris F, et al. Cerebral blood flow in patients with normal pressure hydrocephalus before and after shunting. F Neurosurg 1987;66:379-87.

16 Mamo HL, Meric PC, Ponsin JC, et al. Cerebral blood flow in hydrocephalus. Stroke 1987;18:1074-80.

17 Matsuda M, Nakasu S, Nakazawa T, et al. Cerebral hemodynamics in patients with normal pressure hydrocephalus. Correlation between cerebral circulation time and dementia. Surg Neurol 1990;34:396-401.

18 Kimura M, Tanaka A, Yoshinaga S. Significance of periventricular hemodynamics in normal pressure hydrocephalus. Neurosurgery 1992;30:701-4.

19 Waldemar G, Shmidt Jes F, Delecluse F, et al. High resolution SPECT with $\left({ }^{99 \mathrm{~m}} \mathrm{Tc}\right)-d, l$-HMPAO in normal pressure hydrocephalus before and after shunt operation. $\mathcal{f}$ Neurol Neurosurg Psychiatry 1993;56:655-64.

20 Kristenson B, Malm J, Fagerlund M, et al. Regional cerebral blood flow, white matter abnormalities and cerebrospinal fluid hydrodynamics in patients with idiopathic adult hydrocephalus syndrome. $\mathcal{f}$ Neurol Neurosurg Psychiatry 1996;60:282-8

21 Brooks DJ, Beaney RP, Powell M. Studies on cerebral oxygen metabolism, blood flow, and blood volume, in patients
with hydrocephalus before and after surgical decompression, using positron emission tomography. Brain 1986;109: 613-28.

22 Jagust WJ, Friedland RP, Budinger TF. Positron emission tomography with $\left({ }^{18} \mathrm{~F}\right)$ fluorodeoxyglucose differentiates nomography with ( ${ }^{8} \mathrm{~F}$ ) fluorodeoxyglucose differentiates Neurol Neurosurg Psychiatry 1985;48:1091-6.

23 Tedeschi E, Hasselbach SG, Waldemar G, et al. Heterogeneous cerebral glucose metabolism in normal pressure hydrocephalus. F Neurol Neurosurg Psychiatry 1995;59:608-15.

24 Krauss JK, Droste DW, Vach W, et al. Cerebrospinal fluid shunting in idiopathic normal pressure hydrocephalus of the elderly: effects of periventricular and deep white matter lesions. Neurosurgery 1996;39:292-300.

25 Pickard JD, Newton H, Greene A, et al. A prospective study of idiopathic normal pressure hydrocephalus [abstract]. $\mathcal{F}$ Neurol Neurosurg Psychiatry 1992;55:518.

26 Lezak MD. Neuropsychological assessment, 3rd ed. New York: American Psychological Association, 1995:544-6.

27 Fray PJ, Robbins TW, Sahakian BJ. Neuropsychiatric applications of CANTAB. International fournal of Geriatric Psychiatry 1996;11:329-36.

28 Lawrence AD, Sahakian BJ. Alzheimer's disease and the cholinergic system. Alzheimers Dis Assoc Disord 1995;2: 43-9.

29 Fowler KS, Saling MM, Conway EL, et al. Computerised neuropsychological tests in the early detection of dementia: prospective findings. Fournal of the International Neuroprospective findings. Fournal of the
psychological Society 1997;3:139-46.

30 Sahakian BJ, Morris RG, Evenden JL, et al. A comparative study of visuospatial memory and learning in Alzheimer type dementia and Parkinson's disease. Brain 1988;111 695-718.
31 Owen AM, Morris RG, Sahakian BJ, et al. Double dissociations of memory and executive functions in working lobe excisions or amygdalo-hippocampectomy in man. lobe excisions or amygda

32 Rogers RD, Andrews TC, Grasby PM, et al. Contrasting cortical and sub-cortical PET activations produced by reversal learning and attentional set-shifting in humans. $\mathcal{F}$ Cog Neurosci 2000 (in press).

33 Cockrell JR, Folstein MF. Mini-mental state examination (MMSE). Psychopharmocol Bull 1988;24:689-92.

34 Nelson HE. National adult reading test. Test manual. Windsor: NFER-NELSON, 1982.

35 Beck AT. Depression: causes and treatment. Philadelphia: University of Pennsylvania Press, 1970.

36 Robbins TW, James M, Owen AM, et al. Cambridge neuropsychological test automated battery (CANTAB): a factor analytic study of a large sample of normal elderly volunteers. Dementia 1994;5:266-81.

37 Coull JT, Middleton HC, Robbins TW, et al. Contrasting effects of clonidine and diazepam on tests of working memory and planning. Psychopharmacology 1995;120: 311-21.

38 Semple J, Link CGG. CANTAB parallel battery: a suitable tool for investigating drug effects on cognition. Society for Neuroscience Abstracts 1991;273:10-17.

39 Semple J, Kumar R, Truman MI, et al. The effects of scopoamine hydrobromide upon perfomance of the CANTAB battery. BAP and EBPS Joint Meeting Abstract Book. $\mathcal{F}$ Psychopharmacol 1992:A23.

40 Kendrick DC. Kendrick cognitive tests for the elderly. Test manual. Windsor: NFER-NELSON, 1985.

41 Benton AL, Hamshire K de S. Multilingual aphasia examination. Iowa City: University of Iowa, 1976.

42 Owen AM, Downes JD, Sakakian BJ, et al. Planning and spatial working memory following frontal lobe lesions in man. Neuropsychologia 1990;28:1021-34.

43 Owen AM, Sahakian BJ, Semple J, et al. Visuo-spatial shortterm recognition memory and learning after temporal lobe excisions or amygdalo-hippocampectomy in man. Neuropsychologia 1995;33:1-24.

44 Sahakian BJ, Downes JJ, Eagger S, et al. Sparing of attentional relative to mnemonic function in a subgroup of patients with dementia of the Alzheimer type. Neuropsychologia 1990;28:1197-213.

45 Owen AM, Roberts AC, Polkey CE, et al. Extra-dimensional versus intra-dimensional set shifting performance following frontal lobe excisions, temporal lobe excisions or amygdalo-hippocampectomy in man. Neuropsychologia 1991;29:993-1006.

46 Milner B. Interhemispheric differences in the localisation of psychological processes in man. Br Med Bull 1971;27: 272-7.

47 Downes JJ, Roberts AC, Sahakian BJ, et al. Impaired extradimensional shift performance in medicated and unmedicated Parkinson's disease: evidence for a specific attentional dysfunction. Neuropsychologia 1989;27:1239-43.

48 Owen AM, James M, Leigh PN, et al. Fronto-striatal cognitive deficits at different stages of Parkinson's disease. Brain 1992;115:1727-51.

49 Fazekas F. Magnetic resonance signal abnormalities in asymptomatic individuals: their incidence and functional correlates. Eur Neurol 1989;29:164-8.

50 De Renzi E, Nichelli P. Verbal and non-verbal short term memory impairment following hemispheric damage. Cortex $1971 ; 11: 341-53$.

51 Sahgal A, Lloyd S, Wray C, et al. Does visuospatial memory in Alzheimer's disease depend on the severity of the disorder? International fournal of Geriatric Psychiatry 1992;7: 427-36

52 Sahgal A, McKeith IG, Galloway PH, et al. Do differences in visuospatial ability between senile dementias of the Alzheimer and Lewy body types reflect differences solely in mnemonic function? F Clin Exp Neuropsychol 1995;17:35-43.

53 Robbins TW, Roberts AC, Owen AM, et al. Robbins TW, Roberts AC, Owen AM, et al.
Monoaminergic-dependent cognitive functions of the preMonoaminergic-dependent cognitive functions of the pre-
frontal cortex in monkey and man. Thierry AM, et al, eds. Motor and cognitive functions of the prefrontal cortex. Berlin: Springer Verlag 1994.

54 Lawrence AD, Sahakian BJ, Hodges JR, et al. Executive and mnemonic functions in early Huntington's disease. Brain mnemonic function

55 Brothers L. Brain mechanisms of social cognition. Fournal of Psychopharmacology 1996;10:2-8

56 Fuster JM. Frontal lobes. Curr Opin Neurobiol 1993;3:1605.

57 Stuss DT, Benson DF. Neuropsychological studies of the frontal lobes. Psychol Bull 1984;1:3-28.

58 Mega MS, Cummings JL. Frontal-subcortical circuits and neuropsychiatric disorders. F Neuropsychiatry 1994;6:35870.

59 Whitehouse PJ. The concept of subcortical and cortical dementia: another look. Ann Neurol 1986;19:1-6.

60 Robbins TW, James M, Owen AM, et al. Cognitive deficits in progressive supranuclear palsy, Parkinson's disease and in progressive supranuclear palsy, Parkinson's disease and
multiple system atrophy on tests sensitive to frontal lobe dysfunction. 7 Neurol Neurosurg Psychiatry 1994;57:79-88.

61 Binetti G, Magni E, Padovani A, et al. Executive dysfunction in early Alzheimer's disease. F Neurol Neurosurg Psychiatry 1996;60:91-3.

62 Golomb J, de Leon MJ, George AE, et al. Hippocampal atrophy correlates with severe cognitive impairment in elderly patients with suspected normal pressure hydrocephalus. $\mathscr{f}$ Neurol Neurosurg Psychiatry 1994;57:590-3. 


\section{HISTORICAL NOTE}

\section{Bell's or Friedreich's palsy}

Charles Bell made many important contributions to neurology, ${ }^{12}$ anatomy, and to the world of art. He is commonly remembered for his 1821 paper $^{3}$ to the Royal Society, which provided a brief but unmistakable description of facial paralysis of lower motor neuron type. He clearly separated it from the palsy of upper motor neuron lesions, although this terminology was not then in use. His account of the upturning of the globe was graphic and important, and received more attention from Gowers and later Kinnier Wilson than his account of facial palsy. $\mathrm{He}$ gave his observations in a lecture for the Royal Society in 1826 . He provided a more detailed description in 1829. ${ }^{4}$ His famous paper records a Mr Daniel Quick, gored by a bull, and several other, mostly traumatic causes:

“ . . a man shot with a pistol ball, which entered the ear and tore across the portio dura at its root. .. . The next instance was in a man wounded by the horn of an ox. The point of the horn entered under the angle of the jaw and came out before the ear, tearing across the portio dura.... The forehead of the corresponding side is without motion, the eyelids remaining open, the nostril has no motion in breathing, and the mouth is drawn to the opposite side. The muscles of the face by long disuse are degenerated, and the integuments of the wounded side of the face are become like a membrane stretched over the skull....In this man the sensibility of the face is perfect. The same nerve (portio dura) has been divided in the extirpation of a tumour before the ear, and the immediate effect has been horrible distortion of the face by the prevalence of the muscles of the opposite side, but without loss of sensibility; and that distortion is unhappily increased when a pleasurable emotion should be reflected in the countenance."

The Bell's phenomenon. ${ }^{5}$ was clearly described for the first time in a case history in his 1830 monograph The nervous system of the human body ${ }^{6}$ Moritz Romberg translated this influential volume into German a few years later.

Bell described:

"... a very remarkable turning up of the cornea in an attempt to close the eyelids" and further on

".... the patient is not at all aware of the eye being turned up; although he can turn it up by a voluntary act, and be conscious of it at the same time ...the cornea is still safe although the eye lid does not descend, yet the eye ascends to the eye lid; and it is wiped, cleaned and moistened by the partial performance of the act of winking."

The facial nerve he called "the respiratory nerve of the face. It ministered to the motions of the face which are connected with respiration."

"In all the exhilarating emotions, the eyebrows, eyelids, the nostrils and the angles of the mouth are raised. In the depressing passions it is the reverse."

Bell subsequently corrected an earlier ambiguous remark, that the fifth and seventh cranial nerves innervated the muscles of the face:

"the sensibility of the head and face depend upon the fifth pair of nerves .. the portio dura of the seventh nerve is the principal muscular nerve of the face."

Avicenna had much earlier described spastic, atonic, and convulsive types of facial palsy. ${ }^{7}$ Bell referred to the French neurologist, Roux, who described his own facial nerve paralysis with hyperacusis and altered taste in a letter to Professor Descot. Earlier still was a sketchy account of James Douglas in 1704. (cited by $\left.\operatorname{Bird}^{8}\right)$ However, it was Nikolaus Anton Friedreich (1761-1836), who comprehensively described three cases of peripheral facial paralysis in 1798; the English translation appeared in the Annals of Medicine in $1800 .^{89}$ $\mathrm{He}$ was probably the grandfather of Nikolaus Friedreich of Heidelberg who elucidated hereditary ataxia.

"A man of forty-six years .. . exposed the left side to a stream of cold air from a window. . . .In the morning after a very restless night a very painful swelling, of the size of a hazel nut, appeared in the neighbourhood of the left mastoid process ... the malady was recognized to be rheumatic.... On the morning of the fifth day, our author found the muscles of the left side of the face paralyzed, and the mouth and the nose drawn towards the right side ...the integrity of all the senses, and of all the other muscles of the body, he could not view the evil as apoplectic, but as being local and proceeding from the rheumatism ..."

Various local treatments (aconite, guiac, antimonials, and blisters etc) were applied "for seven weeks without any amendment. ..."

"He employed weak and few electric shocks, but gradually stronger and more numerous . . directed them variously through the left side of the face from that place where the nerve comes through the stylomastoid foramen. ... At last their voluntary action returned by degrees and after electricity had been used for a month, volition had regained its full energy, and the face its natural appearance."

Bell deserves full credit for his account of facial palsy, although the idiopathic condition we now call Bell's palsy was not really part of his description. The variable involvement of the nerve to stapedius causing transient hyperacusis, and the chorda tympani producing impairment of taste were elaborated at a later date, but well described, inter alia, by Todd, Gowers, and Wilson.

J M S PEARCE

304 Beverley Road, Anlaby, Hull HU10 7BG, UK

1 Gordon-Taylor G, Walls EW. Sir Charles Bell his life and times. Edinburgh: Livingstone, 1958

2 Pearce JMS. Sir Charles Bell (1774-1842). $f R$ Soc Med 1993;86:353-4

3 Bell C. On the nerves; giving an account of some experiments on their structure and functions, which lead to a new arrangement of the system. Philos Trans $R$ Soc Lond B Biol Sci 1821;111:398-424.

4 Bell C. On the nerves of the face, being a second paper on that subject. Philos Trans $R$ Soc Lond $B$ Biol Sci 1829;119:317-30. Reprinted in Medical Classics 1936;1:155-67.

5 Zulch,KJ. "Idiopathic" facial paresis. In:Vinken PJ, Bruyn GW, eds. Handbook of clinical neurolPJ, Bruyn GW, eds. Handbook of clinical neurol-
ogy. Amsterdam: North-Holland, 1970:7:241ogy.
96.

6 Bell C. The nervous system of the human body, 2nd ed. London: Longman, 1830; 3rd ed. London: Spottiswode, 1844

7 Gruner OC. A treatise on the canon of medicine of Avicenna incorporating a translation of the first book. London: Luzac, 1930.

8 Bird TD. Nicolaus A. Friedreich's description of peripheral facial nerve paralysis in 1798. 7 Neurol Neurosurg Psychiatry 1979;42:56-8.

9 Friedreich NA. De paralysis musculorum faciei rheumatica. J der Erfindungen (Gotha) 1798;8: 25. Quoted in English by Bird TD in: Annals of Medicine (Edinburgh) 1800;5:214-26. 